\title{
Body Composition in Paraplegia
}

\author{
Yannis Dionyssiotis \\ Additional information is available at the end of the chapter \\ http://dx.doi.org/10.5772/58539
}

\section{Introduction}

Paraplegia leads to immobilisation associated with profound changes in body composition. The potential risks involved with these changes i.e. loss of lean tissue mass (LM) and bone mineral density (BMD) vs. gain in fat mass (FM) in body composition have implications for the health of the disabled individuals [1]. Body fat has been identified as a significant predictor of mortality in humans making body composition measurement to quantify nutritional and health status an important issue for human health [2-4]. Moreover, some disorders such as carbohydrate intolerance, insulin resistance, lipid abnormalities, and heart disease occur prematurely and at a higher prevalence in disabled populations may be related to adverse changes in body composition that result from immobilization and skeletal muscle denervation [5]. To standardize or index physiological variables, such as resting metabolic rate and power fat free mass (FFM) is usually used [4]. Skeletal muscle represents $50 \%$ of the non fat component in the total body $[6,7]$ and exact quantification of the amount of skeletal muscle is important to assess nutritional status, disease risk, danger of illnesses, physical function, atrophic effects of aging, and muscle-wasting diseases $[8,9]$.

A paraplegic subject could be wheelchair bound, may have an alternated walking gait pattern but may also be unable to walk at all $[10,11]$. In addition to these differences and according to osteoporosis the role of factors which do not change, such as race or gender of patients has not been yet clarified, although there are few studies in women debating that bone mass in women with paraplegia is more affected than men [12,13]. Similar findings of reduced muscle mass and increased intramuscular fat have been also published in individuals with incomplete spinal cord injury (SCI) [14].

Therefore, the purpose of this chapter was to present the bone-mineral density, bone-mineral content, and bone-mineral-free lean and fat tissue mass alterations of ambulatory and nonambulatory subjects with paraplegia. 


\section{Body composition measurements}

\subsection{Anthropometric and various techniques of body composition measurements}

Similar body mass indices were found between paraplegics and controls; although there were significant decreases in the lean muscle mass of the paraplegics (16\% less). The analysis of body composition with dual-energy X-ray absorptiometry (DXA) has also revealed large increases in fat in people who do not appear to be obese, yet they carry large amounts of fat tissue and in the group of paraplegic subjects fat mass was $47 \%$ higher [15]. Furthermore, where authors performed a research in the usage of the body mass index (BMI) in anthropometric measurements, the conclusion was that BMI, widely used as an obesity measurement tool, is not capable of distinguishing the weight components among people so that the fat percentage is degraded in the population of paraplegic in comparison to the control group [16].

In a study which investigated a chronic paraplegic population the values of BMI did not present statistical significance in relation to the controls, which is a finding in line with the literature $[17,18,19]$. Moreover, the values of $\mathrm{BMI}$ in both paraplegics and controls were below values consider to signify obesity (BMI $>27.8)[19,20,21]$. This finding could be acceptable for the population of the controls, but raises questions regarding the paraplegics. It is known from literature that paraplegics are obese [22]. Nevertheless, there are studies which demonstrate the usefulness of BMI as an indicator of obesity, in body composition in people with spinal cord injury [23]. These studies, however, included in their sample both tetraplegics and middle-aged people unlike the Greek one which included relatively young individuals [19]. Whether the criteria of BMI may assess obesity in people with spinal cord injury the latest studies show the opposite [24].

Similarly to the healthy population values of BMI are positively correlated with obesity. This emerged from a study, conducted by whole body DXA Norland X-36, only when the findings of total fat in paraplegics were correlated with BMI. Employing whole body DXA Norland XR-36 it was found that the total fat mass was statistically significantly higher for any given BMI value in paraplegics compared with controls [19], finding that strongly supports the studies held by the whole body DXA Hologic QDR-2000 method [5, 25].

The studies illustrated statistically significantly higher total fat mass and fat percentages for any given unit of body mass index in paraplegics in comparison to controls. Increased fat per body mass index unit was found in a study of monozygotic twins, one with SCI compared with a non-SCI co-twin by the above authors also [25]. Adjustments in classifications of normal, overweight, obese, and morbid obesity by BMI are needed for persons with SCI [26].

In addition, by analysis between paraplegics with high and low neurological level injuries not statistically significant differences in BMI were highlighted. However, when data from the analysis undertaken in areas measured by the method of whole body DEXA were compared in the same patients there were differences between paraplegics with high and low neurological level of injury. This finding is new and reinforces those views on the inability of BMI usage in the analysis of body composition of paraplegics [19]. 
BMI of the male paraplegic group was slightly greater than that of the male tetraplegic group ( $\left.25.2 \mathrm{vs.} 24.7 \mathrm{~kg} / \mathrm{m}^{2} ; \mathrm{p}<0.01\right)$. Proportion of overweight or obese was comparable between men with SCI and that observed in men in the US general population. Distribution of BMI by level of injury was similar with $37.5 \%$ and $40.5 \%$ of the male tetraplegic and male paraplegic groups, respectively, falling into the recommended BMI range. Approximately $50 \%$ in each male group were overweight by BMI, and $12.5 \%$ and $10.8 \%$, respectively, were classified as obese. Overall, when compared with the general population-observed distribution by BMI, a greater proportion of men with SCI fell into the desirable BMI range and fewer fell into the obese category [26].

No differences were found in BMI between paraplegics in the acute phase of injury and controls, which is a finding in accordance with other studies reported in chronic paraplegic patients and controls, in which despite the same BMI the body composition and the distribution of fat and fat free mass were alterated in patients with spinal cord damage, with the fat free mass being statistically significantly lower in paraplegic patients in total body composition and in the lower, but not the upper limbs. As far as the fat mass is concerned, it was statistically significantly higher (kilograms and \%) in the total body composition in the upper and lower limbs [27].

These findings show that using the BMI does not contribute substantially in determining the body composition of paraplegics and lowers the percentage of fat in this population, finding that agrees with other studies and shows that the anthropometric measurement with BMI in paraplegics, underestimates fat in body composition when measurements are compared with healthy subjects [1].

Changes in body composition in spinal cord injured subjects can be assessed with various techniques including isotope-labelled water [1] total body potassium counting (Lussier et al 1983; Spungen et al 1992) anthropometric measures [16] hydrodensitometry [28] dual photon absorptiometry (DPA) [29] and dual energy X-ray absorptiometry (DXA) [1]. However, some of these methods are not particularly suitable for use in the SCI population.

The hydrodensitometric model was regarded as the "gold standard" for body composition assessment. This model partitions the body into two compartments of constant densities [fat mass: $0.9007 \mathrm{~g} / \mathrm{cm}^{3}$ and FFM: $1.100 \mathrm{~g} / \mathrm{cm}^{3}$ ] and assumes that the relative amounts of the FFM components [water, protein, protein, bone mineral (BM), and non-BM] are fixed [4]. Hydrodensitometry is clearly inappropriate for individuals who deviate from these fixed and/or assumed values (e.g., children, elderly, blacks, obese), and its application is, therefore, somewhat limited $[30,31]$.

Bioelectrical impedance analysis has been used to measure cerebral palsy subjects. However, the inclusion of weight in the BIA predictive equation may reduce its accuracy in determining change in lean body mass. The inability of BIA to accurately predict percentage body fat in the sample may be related to several factors. In the BIA method where the impedance of a geometrical system (i.e., the human body) is dependent on the length of the conductor (height) and its configuration, it is almost impossible to measure accurately height in subjects with $\mathrm{CP}$ because of their muscle contractures. An over-or underestimation of height by $2.5 \mathrm{~cm}$ can result in a 1.0-L error in the estimation of TBW, producing a small error in the estimation of percentage 
body fat $(<5 \%)$. The second major problem is body asymmetry which renders the assumption of a symmetrical configuration of the human body invalid in this case [20,32].

Isotope dilution measures the water compartment of the whole body rather than a single area assumed to mimic the composition of the whole body. Thus, the use of a stable isotope to measure body composition is ideal for people with $\mathrm{CP}$ because it is non-invasive, does not require the subject to remain still for the measurement, and is independent of height and body symmetry. However, the prohibitive cost of the isotopes and the need for a mass spectrometry facility and highly trained technicians make this method impractical for routine clinical use [32].

To determine whether bioelectrical impedance analysis (BIA) and anthropometry can be used to determine body composition for clinical and research purposes in children with cerebral palsy 8 individuals (two female, mean age $=10$ years, mean gross motor function classification=4.6 [severe motor impairment]) recruited from an outpatient tertiary care setting underwent measurement of fat mass, fat-free mass, and percentage body fat using BIA, anthropometry (two and four skinfold equations), and dual-energy x-ray absorptiometry. Correlation were excellent for determination of fat-free mass for all methods (i.e., all were above 0.9 ) and moderate for determination of fat mass and percent body fat (range $=0.4$ to 0.8 ). Moreover, skinfolds were better predictors of percent body fat, while bioelectrical impedance was a better predictor for fat mass [33]. On the contrary another study investigated the pattern of body composition in 136 subjects with spastic quadriplegic cerebral palsy, 2 to 12 years of age, by anthropometric measures, or by anthropometric and total body water (TBW) measures $(\mathrm{n}=28)$, compared with 39 control subjects. Body composition and nutritional status indicators were significantly reduced. Calculation of body fat from two skinfolds correlated best with measures of fat mass from TBW [34].

Magnetic resonance imaging (MRI) provides remarkably accurate estimates of skeletal muscle in vivo [7]. MRI and also quantitative computed tomography (QCT) have been validated in studies of humancadavers in the assessment of regional skeletal muscle [35]. Although, these devices have disadvantages of high radiation exposure and are expensive.

\subsection{Dual-energy X-ray absorptiometry (DXA)}

Recently, dual-energy X-ray absorptiometry (DXA) has gained acceptance as a reference method for body composition analysis $[36,37]$. Originally designed to determine bone density, DXA technology has subsequently been adopted for the assessment of whole body composition and offers estimation rapidly, non-invasively and with minimal radiation exposure [4, 19]. Moreover, is well tolerated in subjects who would be unable to tolerate other body composition techniques, such as underwater weighing (hydro-densitometry). DXA software determines the bone mineral and soft tissue composition in different regions of the body being a three-compartment model that quantifies: (i) bone mineral density and content (BMD, BMC), (ii) fat mass (FM); and (iii) lean mass (LM), half of which is closely correlated with muscle mass and also yields regional as well as total body values [38] for example in the arms, legs, and trunk (figure 1). 


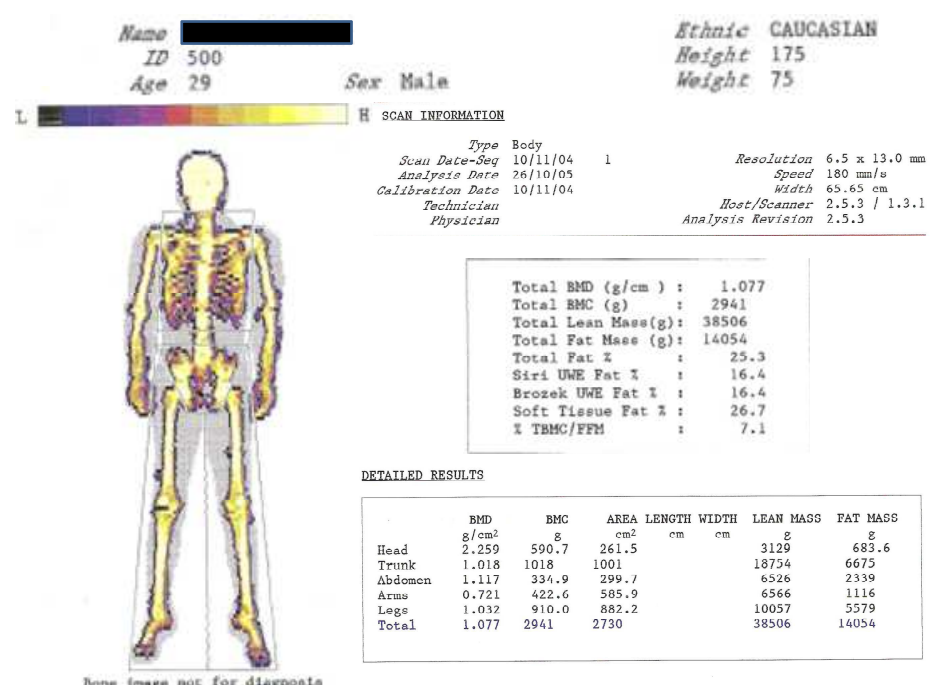

Figure 1. Whole body and regional distribution of fat mass, lean mass, bone mineral content (BMC) and bone mineral density (BMD) from paraplegic subject thoracic 6 using whole body DXA (Norland X-36, Fort Atkinson, Wisconsin, USA) and values of measured parameters. Modified and translated with permission from Dionyssiotis Y, Doctoral Dissertation, Laboratory for Research of the Musculoskeletal System, University of Athens, 2008 [39].

DXA analyzes differently the dense pixels in body composition. Soft tissue pixels are analyzed for two materials: fat and fat-free tissue mass. Variations in the fat mass/fat free tissue mass composition of the soft tissue produce differences in the respective attenuation coefficients at both energy levels. The ratio at the two main energy peaks is automatically calculated of the X-ray attenuation providing separation of the soft tissue compartment into fat mass and fat-free tissue mass (lean mass) [40, 41]. A bone-containing pixel is analyzed for "bone mass" (bone mineral content, BMC) and soft tissue as the two materials. Thus, the fat mass/fat free tissue mass of the soft tissue component of the bone pixels cannot be measured, but only estimated [42].

The important issue on this the investigation of distribution of bone mineral, fat and mass throughout the body. These changes induce the risk for diseases such as diabetes, coronary heart disease, dyslipidaimias and osteoporosis [22, 43, 44, 45]. There is a need to quantify the alterations in body composition to prevent these diseases and their complications. Studies also reported that bone density measurements at one site cannot usefully predict the bone density elsewhere [46] because different skeletal regions, even with similar quantities of trabecular or cortical bone, may respond variably in different physiopathological conditions [47].

In disabled conditions the accuracy of skeletal muscle measured by DXA may be compromised when muscle atrophy is present. A lower ratio of muscle to adipose-tissue-free mass indicates a lower proportion of muscle in the fat-free soft tissue mass. Cross-sectional area of skeletal muscle in the thighs after SCI is extensively reduced [48]. If this is the case 
muscle mass would be overestimated by prediction models that assume that muscle represents all or a certain proportion of the fat-free soft tissue mass, i.e. in spinal cord injured subjects [7]. DXA technique has been used in assessment of SCI and appears to be tolerated well by this population $[49,50,51]$.

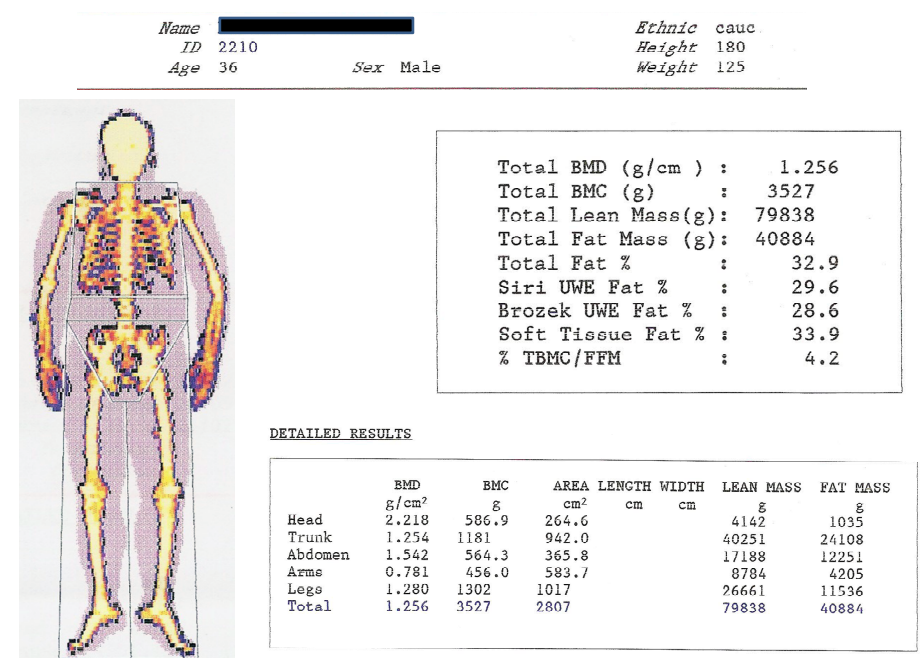

Figure 2. Whole body and regional distribution of fat mass, lean mass, bone mineral content (BMC) and bone mineral density (BMD) from controls male subject using whole body DEXA Norland X-36 and values of measured parameters. Modified and translated with permission from Dionyssiotis, Doctoral Dissertation, Laboratory for Research of the Musculoskeletal System, University of Athens, 2008 [39].

\section{Physiopathological context}

Spinal cord injury (SCI) always results in substantial and rapid bone loss predominately in areas below the neurological level of injury. The predominant finding of SCI on bone is a large loss of bone during the first year of injury [5] and an ongoing demineralisation 3 years after trauma in tibia [52] with a progressive bone loss over 12 to 16 months prior to stabilizing [53] was demonstrated.

Cancellous bone is more affected than cortical bone after SCI. In a prospective study, six acute tetraplegics were followed up for 12 months, and the trabecular and cortical BMD's of the tibia were found to be decreased by 15 and 7\% [54], while in paraplegics trabecular metaphysicalepiphyseal areas of the distal femur and the proximal tibia are the most affected sites [55]. A cross-sectional study [56] in SCI subjects demonstrated a significant demineralization at the distal femur (-52\%) and the proximal tibia $(-70 \%)$, respectively.

There is no demineralization of the upper limbs in paraplegics. On the contrary, a minor increase of $\mathrm{BMD}(6 \%)$ in the humerus was reported in a cross-sectional study of 31 male chronic 
paraplegics 1 year post injury. With reliance on the upper limbs to provide movement for activities of daily living in the SCI population, this area could be subjected to greater sitespecific loading, and thus increasing osteogenesis, than in the corresponding able-bodied population. At the lumbar spine, the trabecular bone demineralization remains relatively low compared to the cortical bone demineralization of long bones [56]. Normal [52,57] or even higher than normal [58] values of BMD in the lumbar spine have been reported a phenomenon is named "dissociated hip and spine demineralization" [54]. One reason for preservation of bone mass in the vertebral column is because of its continued weight-bearing function in paraplegics. In a cross-sectional study of 135 SCI men, BMD in the lumbar spine was found to be stable with an insignificant decline in the tetraplegic population at $1 \pm 5$ years post injury in the 20-39-year age group, whereas in the 40-59-year age group and the 60+-year age group, bone mass in the lumbar spine remained unchanged or even increased with age [49]. However, several factors may affect the results of BMD measurement: lumbar spine arthrosis, bone callus, vertebral fracture, aortic calcification, osteosynthesis material, etc. Degenerative changes in the spine may be the most possible reason to give falsely higher values of BMD [56]. An interesting question is why we don't see osteoporotic vertebral fractures in SCI patients to the extent it occurs in post-menopausal osteoporotic women or senile osteoporotic men?

Figure 3 depicts the analysis of bone mineral density (BMD) in high and low level paraplegics and controls. A statistically significant reduction in total BMD $(p<0.001)$ and lower limbs BMD in body composition compared to able-bodied males was observed. On the contrary, upper limbs BMD was higher in low paraplegics and controls, an unexpected finding explained in the paper of Dionyssiotis et al. [19].

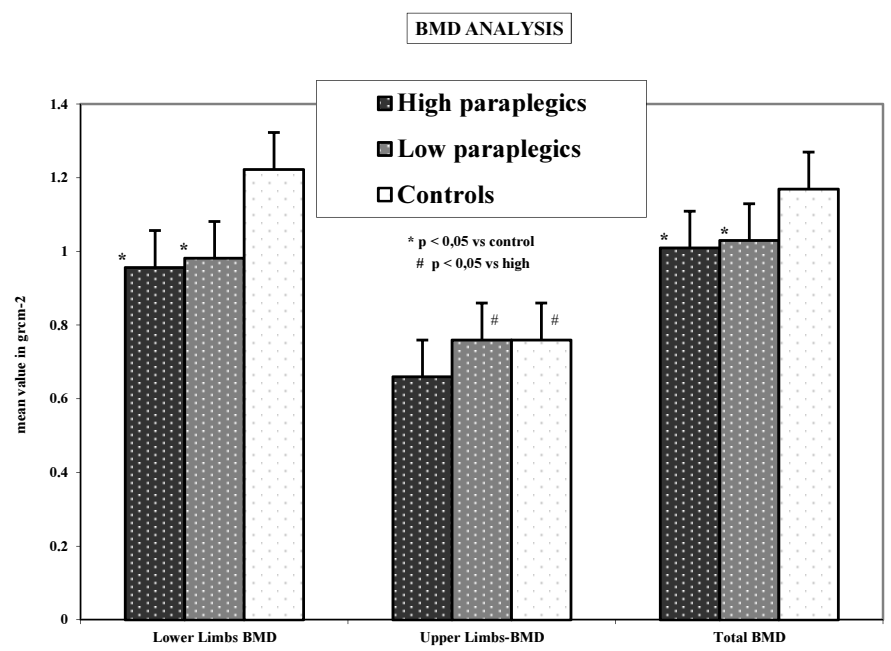

Figure 3. Analysis of bone mineral density (BMD) in high and low level paraplegics and controls. Diagram modified and translated from Dionyssiotis Y [39]. 
The neurological level of the lesion i.e. the extent of impairment of motor and sensory function is important, because tetraplegics are more likely to lose more bone mass throughout the skeleton than paraplegics [60]. In paraplegics legs' BMC was reduced vs. controls, independently of the neurological level of injury and negatively correlated with the duration of paralysis in total paraplegic group, but after investigation according to the neurological level of injury this correlation was due to the strong correlation of high paraplegics' legs BMC with the duration of paralysis, meaning that the neurological level of injury determines the extent of bone loss [61]. The similar severity of demineralization in the sublesional area was shown between paraplegics and tetraplegics, and the extent of the bone loss may be variable [56, 60,62].

In addition, in those SCI individuals with complete lesions (an absence of sensory or motor function below the neurological level, including the lowest sacral segment) bone loss is more severe than subjects with incomplete lesions (partial preservation of motor and/or sensory function below the neurological level, including the lowest sacral segment) [62, 63]. In a crosssectional study of 11 patients with complete SCI and 30 patients with incomplete SCI noticed a significant osteopenia in patients with complete SCI than in patients with incomplete SCI [62].

The duration of paralysis has an inverse relationship with leg percentage-matched BMD and trunk percentage-matched BMD [64]. In addition in complete paraplegics, with high (thoracic 4-7) and low (thoracic 8-12) neurological level of injury, upper limbs FM and lower limbs BMD were correlated with the duration of paralysis in total paraplegic group but after investigation according the neurological level of injury this correlation was due to the strong correlation of high paraplegics' lower limbs BMD with the duration of paralysis. The explanation of this strong correlation could possibly lie on higher incidence of standing in the group of low paraplegics and direct effect of loading lower limbs while standing and walking with orthotic equipment. Moreover, the association of the duration of paralysis with parameters below and above the neurological level of injury (upper limbs FM) raises the question of the existence of a hormonal mechanism as an influential regulator in paraplegics' body composition $[19,61,65]$.

Is there a time after injury where bone loss ceases? Some authors reported that approximately 2 years after SCI, a new steady state level between bone resorption and formation would be re-established [52,57], whereas others [66] found that there was no sign of a new steady state in bone formation in the lower extremities 2 years after the SCI. If a new steady state of bone remodelling is re-established after SCI still remains controversial.

Inconsistent results have been reported regarding the effect of muscle spasms on BMD in SCI patients. Those with spasticity were found with higher BMD when compared with flaccid individuals [62], and a significant correlation between the degree of spasticity measured with modified Ashworth scale and BMD was reported. Thus, it was concluded that spasticity may be protective against bone loss in SCI patients [67]; however, without any preserving effect in the tibia $[65,67]$. A possible explanation for that could lie in the fact paraplegics to be above thoracic (T)12 level with various degrees of spasticity according to the Ashworth scale. In addition, muscle spasms affecting the lower leg would mainly be extension spasms resulting in plantar flexion thus creating little resistance to the contracting muscles. Furthermore, the measuring sites of the tibia did not include any muscle insertions of either the knee or the ankle 
extensor muscles [65]. Other investigators have not established a correlation between BMD and muscle spasticity [68].

Studies also emphasize the contribution of aging to bone loss in complete SCI patients. Moderate correlation between age and femoral BMD was observed in a cross-sectional study of 30 patients with SCI of 1-year duration or less [69]. On the other side bone loss in eight pairs of identical male twins with SCI of duration ranging from 3 to 26 years appeared to be independent of age [70].

Muscular loading of the bones has been thought to play a role in the maintenance of bone density. The ability to stand or ambulate itself does not improve BMD and does not prevent osteoporosis after SCI, although exercise increases site-specific osteogenesis in able-bodied individuals [71]. There was only one study demonstrating that standing might reduce the loss of trabecular bone after SCI. In this prospective study of 19 acute SCI patients, the patients involved in early loading intervention exercise lost almost no bone mineral, whereas the immobilization patients lost 6.9 to $9.4 \%$ of trabecular bone [66].

Muscles rather than body weight are causing the greatest loads on bone [72]. It is difficult to translate in vivo bone strains from animal work to a gross loading environment for humans. However, the pioneering work in animal models [73] suggests that if the activeresistive standing exercise can indeed transmit loads at an appropriate frequency and strainrate, compressive loads approaching $240 \%$ body weight may have the potential to be osteogenic [73, 74].

FES cycling [75] and quadriceps muscle training [76] have been able to increase forcegenerating capability and to improve muscular endurance with training after SCI [75]. Conversely, cycling with FES has been reported to induce only small improvements in BMD $[77,78]$ as well as have no effect [78] on lower extremity BMD measurements in individuals with SCI. Additionally, neither passive standing, ambulation with long-leg braces, nor ambulation with FES have yet to exhibit any improvement in lower extremity BMD in chronically injured subjects [79]. The subject populations of previous BMD studies were comprised almost exclusively of individuals with chronic rather than acute SCI. these interventional BMD studies may have utilized sub-threshold mechanical stimuli. The use of relatively low bone loading regimens is not unexpected due to the extensive atrophy of chronically paralyzed muscle $[80,81]$ and concerns of fracture, which have been reported to occur with physical interventions $[82,83]$.

The role of leptin: The hormone leptin is secreted by fat cells and help regulate body weight and energy consumption [84]. The amount of leptin in the circulation is positively correlated with the percentage of fat in people [85]. In paraplegics, when compared with healthy subjects, higher levels of leptin have been found, possibly due to greater fat tissue storage [86, 87]. Leptin activates the sympathetic nervous system (SNS) through a central administration. The disruption of the sympathetic nervous system may modify the secretion and activity of the leptin, because the sympathetic preganglionic neurons become atrophic in high paraplegics $[88,89]$. The irritation thus, below the neurological level of injury, from the leptin is disturbed. In addition, extensive obesity is known to reduce lipolytic sensitivity [89, 90, 91]. Given that 
in the high level of neurological paraplegia there is a problem of disorder of the autonomic nervous system and in combination with the existence of scientific evidence that the hormone leptin activates the sympathetic nervous system through central control, was formulated, that the closure <of paths $>$ of the central nervous system disrupts the effect of leptin and possibly increases the risk of obesity in paraplegic patients with high-level injury [92, 93].

However, after separation of SCI subjects into those with an injury above or below Thoracic (T) 6, leptin levels were significantly higher in the former group. T6 appears to be the lowest level of injury in most patients with SCI to develop autonomic dysreflexia. With SCIs above the level of T6, there is reduced SNS outflow and supraspinal control to the splanchnic outflow and the lower-extremity blood vessels. Multiple regression analysis showed that serum leptin levels in men with SCI correlated not only with BMI but also with the neurologic deficit. This finding supports the notion that decentralization of sympathetic nervous activity relieves its inhibitory tone on leptin secretion, because subjects with tetraplegia have a more severe deficit of sympathetic nervous activity [94].

Actually, little is known regarding the nature and time frame of the influence of complete SCI on human skeletal muscle because published data are coming from cross-sectional studies, where different groups with few subjects have been examined at different times, usually in the chronic phase of paralysis. Disuse was thought to be the mechanism responsible for the skeletal muscle atrophy in paraplegics, but muscle fibres following SCI begin to change their functional properties early post injury. Muscle fiber cross-sectional area (CSA) has been suggested to decline from 1 to 17 months after injury and thereafter to reach its nadir. Conversion to type II fibers has been suggested to occur between 4 months and 2 years after injury, resulting in even slow-twitch muscle becoming predominantly fast twitch thereafter (Castro et al 1999). Metabolic enzymes levels in skeletal muscle might be expected to be reduced after SCI because of inactivation. In support of this contention, succinic dehydrogenase (SDH) activity, a marker of aerobic-oxidative capacity, has been reported to be $47-68 \%$ below control values in fibers of tibialis anterior muscle years after injury in support of this contention [95].

The muscle atrophy in SCI is of central type and depends on the disuse and loss of upper connections of the lower motor neuron, sometimes associated to the loss of anterior horn cells and transinaptic degeneration. The last alteration may be responsible for the denervation changes seen in early stages post SCI. In the later stages (10-17 months post SCI) diffuse muscle atrophy with reduction of the muscle fascicle dimension is associated to fat infiltration and endomysial fibrosis. In all stages post SCI, almost all patients showed myopathic changes, as internal nuclei, fibre degeneration and cytoplasmic vacuolation due to lipid accumulation [95].

It is evident that other co-factors as spasticity and microvascular damage, contribute to the induction of the marked morphological and enzyme histochemical changes seen in the paralyzed skeletal muscle [95]. Small fibers, predominantly fast-twitch muscle, and low mitochondrial content have been reported years after injury in cross-sectional studies. These data have been interpreted to suggest that human skeletal muscle shows plasticity [48].

On the contrary, force loss during repetitive contractions evoked by surface electrical stimulation (ES) of skeletal muscle in humans does not appear to be altered within a few months of 
injury [80] but it is greater a year or more after SCI (Hillegass and Dudley, unpublished observations). The greater fatigue, when evident, was partially attributed to lower metabolic enzyme levels [95].

Muscular loading of the bones has been thought to play a role in the maintenance of bone density $[65,66]$. However, the ability to stand or ambulate itself does not improve BMD or prevent osteoporosis after SCI.

\section{Conclusions}

Other important issues according alterations of body composition are the completeness of lesions (an absence of sensory or motor function below the neurological level, including the lowest sacral segment), because body composition seems to be worse than subjects with incomplete lesions (partial preservation of motor and/or sensory function below the neurological level, including the lowest sacral segment) and aging which contributes to major alterations of body composition [62, 63].

In disabled subjects the most important issue according to body composition is how to promote optimal body weight to reduce risk of diseases such as coronary heart disease, non-insulin dependent diabetes mellitus, lipid abnormalities and fractures because of bone loss. Dietary changes, individualized physical activity programs and medication should be taken in mind in therapy when we deal with this subgroup of subjects. However, self-management of dietary changes to improve weight control and disease should be the case, which means they need to follow diets with lower energy intake and at the same time to eat regularly foods rich in nutrients [26].

We need to take in mind that healthy BMI values often underestimate body fat and may mask the adiposity and spasticity did not defend skeletal muscle mass and bone, supporting the concept that in neurologic disabilities the myopathic muscle could not recognize correctly the stimulation because of the neurogenic injury. Moreover, disabled subjects mostly transfer much of the weight-bearing demands of daily activities to their upper extremities reducing the weight-bearing of the affected paralyzed muscles triggering a cycle of added muscle atrophy which interacts with the continuous catabolic action caused by the neurogenic factor. Finally, an irreversible (once established) decline in bone mineral density, bone mineral content as well as geometric characteristics of bone is expected and the duration of lesion-injury is positively correlated with the degree of bone loss.

Further research about body composition is needed in all physical disabilities and more longitudinal studies to quantitate and monitor body composition changes and to modify our therapeutic interventions. However, prevention rather than treatment may have the greatest potential to alleviate these major complications. Therapies should focus on how to perform weight bearing, standing or therapeutically walking activities early in the rehabilitation program to gain benefits according to muscles and bones. 


\section{Author details}

Yannis Dionyssiotis ${ }^{1,2^{*}}$

1 Rehabilitation Center "Aghios Loukas o Iatros”, Trikala Thessaly, Greece

2 University of Athens, 1st Department of Orthopaedics, General University Hospital Attikon, Athens, Greece

\section{References}

[1] Jones LM, Goulding A, Gerrard DF. DEXA: a practical and accurate tool to demonstrate total and regional boneloss, lean tissue loss and fat mass gain in paraplegia. Spinal Cord. 1998;36:637-40

[2] Seidell JC, Verschuren WM, van Leer EM, Kromhout D. Overweight, underweight, and mortality. A prospective study of 48.287 men and women. Arch Intern Med. 1996;156:958-63.

[3] Bender R, Trautner C, Spraul M, Berger M. Assessment of excess mortality in obesity. Am J Epidemiol. 1998;147:42-8.

[4] Van Der Ploeg GE, Withers RT, Laforgia J. Percent body fat via DEXA: comparison with a four-compartment model. J Appl Physiol. 2003;94:499-506.

[5] Spungen AM, Adkins RH, Stewart CA, Wang J, Pierson RN Jr, Waters RL, Bauman WA. Factors influencing body composition in persons with spinal cord injury: a cross-sectional study. J Appl Physiol. 2003;95: 2398-2407.

[6] Clarys JP, Martin AD, Drinkwater DT. Gross tissue weights in the human body by cadaver dissection. Hum Biol. 1984;56:459-73.

[7] Modlesky CM, Bickel CS, Slade JM, Meyer RA, Cureton KJ, Dudley GA. Assessment of skeletal muscle mass in men with spinal cord injury using dual-energy X-ray absorptiometry and magnetic resonance imaging. J Appl Physiol. 2004;96:561-5.

[8] Forbes GB. Human body composition: growth, aging, nutrition, and activity. New York: Springer-Verlag; 1987.

[9] Mojtahedi MC, Valentine RJ, Arngrímsson SA, Wilund KR, Evans EM. The association between regional body composition and metabolic outcomes in athletes with spinal cord injury. Spinal Cord. 2008;46:192-7.

[10] Dionyssiotis Y. (2011). Bone Loss in Spinal Cord Injury and Multiple Sclerosis. In: JH Stone, M Blouin, editors. International Encyclopedia of Rehabilitation, av. online: http://cirrie.buffalo.edu/encyclopedia/en/article/340/ 
[11] Dionyssiotis Y. Spinal cord injury-related bone impairment and fractures: an updateon epidemiology and physiopathological mechanisms. J Musculoskelet Neuronal Interact. 2011;11:257-65.

[12] Smeltzer SC, Zimmerman V, Capriotti T. Osteoporosis risk and low bone mineral density in women with physical disabilities. Arch Phys Med Rehabil. 2005;86:582-6.

[13] Coupaud S, McLean AN, Allan DB. Role of peripheral quantitative computed tomography in identifying disuse osteoporosis in paraplegia. Skeletal Radiol. 2009; 38:989-95.

[14] Gorgey AS, Dudley GA. Skeletal muscle atrophy and increased intramuscular fat after incomplete spinal cord injury. Spinal Cord. 2007;45:304-9.

[15] Jones LM, Legge M, Goulding A. Healthy body mass index values often underestimate body fat in men with spinal cord injury. Arch Phys Med Rehabil. 2003;84:1068-71.

[16] Bulbulian R, Johnson RE, Gruber JJ, Darabos B. Body composition in paraplegic male athletes. Med Sci Sports Exerc. 1987;19:195-201.

[17] Maggioni M, Bertoli S, Margonato V, Merati G, Veicsteinas A, Testolin G. Body composition assessment in spinal cord injury subjects. Acta Diabetol. 2003;40:S183-6.

[18] Mamoun L, Puech AM, Manetta J, Badiou S, Paris F, Ohanna F, Rossi M, Sultan C. Circulating leptin concentrations can be used as a surrogate marker of fat mass in acute spinal cord injury patients. Metabolism. 2004;53:989-94.

[19] Dionyssiotis $\Upsilon$, Petropoulou K, Rapidi CA, Papagelopoulos PJ, Papaioannou N, Galanos A, Papadaki P, and Lyritis GP. Body Composition in Paraplegic Men. Journal of Clinical Densitometry. 2008;11: 437-43.

[20] National Institutes of Health Consensus Development Conference Statement. Health implications of obesity. Natl Inst Health Consens Dev Conf Consens Statement. $1985 ; 5: 1-7$.

[21] Schulte PA, Wagner GR, Ostry A, Blanciforti LA, Cutlip RG, Krajnak KM, Luster M, Munson AE, O'Callaghan JP, Parks CG, Simeonova PP, Miller DB. Work, obesity, and occupational safety and health. Am J Public Health. 2007;97:428-36.

[22] Kocina P. Body composition of spinal cord injured adults. Sports Medicine. 1997;23:48-60.

[23] Gupta N, White KT, Sandford PR. Body mass index in spinal cord injury -- a retrospective study. Spinal Cord. 2006;44:92-4.

[24] McDonald CM, Abresch-Meyer AL, Nelson MD, Widman LM. Body mass index and body composition measures by dual x-ray absorptiometry in patients aged 10 to 21 years with spinal cord injury. J Spinal Cord Med. 2007;30:S97-104. 
[25] Spungen AM, Wang J, Pierson RN, Jr., Bauman WA. Soft tissue body composition differences in monozygotic twins discordant for spinal cord injury. J Appl Physiol. 2000;88:1310-5.

[26] Groah SL, Nash MS, Ljungberg IH, Libin A, Hamm LF, Ward E, Burns PA, Enfield G. Nutrient intake and body habitus after spinal cord injury: an analysis by sex and level of injury. J Spinal Cord Med. 2009;32:25-33.

[27] Maimoun L, Fattal C, Micallef JP, Peruchon E, Rabischong P. Bone loss in spinal cord-injured patients: from physiopathology to therapy. Spinal Cord. 2006;44:203-10.

[28] Lussier L, Knight J, Bell G, Lohman T, Morris AF. Body composition comparison in two elite female wheelchair athletes. Paraplegia. 1983;21:16-22.

[29] Spungen AM, Bauman WA, Wang J, Pierson RN. Reduced quality of fat free mass in paraplegia. Clin Research. 1992;40:280A.

[30] Womersley J, Durnin JV, Boddy K, Mahaffy M. Influence of muscular development, obesity, and age on the fat-free mass of adults. J Appl Physiol. 1976;41:223-9.

[31] Fuller NJ, Sawyer MB, Laskey MA, Paxton P, Elia M: Prediction of body composition in elderly men over 75 years of age. Ann Hum Biol. 1996;23:127-47.

[32] Hildreth HG, Johnson RK, Goran MI, Contompasis SH. Body composition in adults with cerebral palsy by dual-energy X-ray absorptiometry, bioelectrical impedance analysis, and skinfold anthropometry compared with the $18 \mathrm{O}$ isotope-dilution technique. Am J Clin Nutr. 1997;66:1436-42.

[33] Liu LF, Roberts R, Moyer-Mileur L, Samson-Fang L. Determination of body composition in children with cerebral palsy: bioelectrical impedance analysis and anthropometry vs dual-energy x-ray absorptiometry. J Am Diet Assoc. 2005;105:794-7.

[34] Kuperminc MN, Stevenson RD. Growth and nutrition disorders in children with cerebral palsy. Dev Disabil Res Rev. 2008;14:137-46.

[35] Mitsiopoulos N, Baumgartner RN, Heymsfield SB, Lyons W, Gallagher D, and Ross R. Cadaver validation of skeletal muscle measurement by magnetic resonance imaging and computerized tomography. J Appl Physiol. 1998;85:115-22.

[36] Mahon AK, Flynn MG, Iglay HB, Stewart LK, Johnson CA, McFarlin BK, Campbell WW. Measurement of body composition changes with weight loss in postmenopausal women: comparison of methods. J Nutr Health Aging. 2007;11:203-13.

[37] LaForgia J, Dollman J, Dale MJ, Withers RT, Hill AM. Validation of DXA body composition estimates in obese men and women. Obesity (Silver Spring). 2009;17:821-6.

[38] Rittweger J, Beller G, Ehrig J, Jung C, Koch U, Ramolla J, Schmidt F, Newitt D, Majumdar S, Schiessl H, Felsenberg D. Bone-muscle strength indices for the human lower leg. Bone. 2000;27:319-26. 
[39] Dionyssiotis Y. Changes in bone density and strength of the tibia and alterations of lean and fat mass in chronic paraplegic men. Doctoral Dissertation Laboratory for Research of the Musculoskeletal System, University of Athens, Athens 2008.

[40] Peppler WW, Mazess RB. 1981. Total body bone mineral and lean body mass by dual-photon absorptiometry. Calcif Tissue Int 33:353-359

[41] Pietrobelli A, Formica C, Wang AM, Heymsfield SB. 1996. Dual-energy X-ray absorptiometry body composition model: review of physical concepts. Am J Physiol 271 (Endocrinol Metab 34): E941-E951

[42] Ferretti J.L., Cointry G.R., Capozza R.F., Zanchetta J.R. Dual energy X-ray absorptiometry. Skeletal Muscle: Pathology, Diagnosis and Management of Disease. V.R.Preedy, T.J.Peters (eds),Greenwich Medical Media, Ltd., London, 2001; p.451-458.

[43] Bauman WA, Spungen AM, Raza M, Rothstein J, Zhang RL, Zhong YG, Tsuruta M, Shahidi R, Pierson RN Jr, Wang J, et al. Coronary artery disease: metabolic risk factors and latent disease in individuals with paraplegia. Mt Sinai J Med. 1992;59:163-8.

[44] Bauman WA, Spungen AM. Disorders of carbohydrate and lipid metabolism inveterans with paraplegia or quadriplegia: A model of premature aging. Metabolism. 1994;43:749-56.

[45] Garland DE, Stewart CA, Adkins RH, Hu SS, Rosen C, Liotta FJ, Weinstein DA Osteoporosis after spinal cord injury. J Orthop Res. 1992;10:371-8.

[46] Heymsfield SB, Wang J, Heshka S, Kehayias JJ, Pierson RN. Dual-photon absorptiometry: comparison of bone mineral and soft tissue mass measurements in vivo with established methods. Am J Clin Nutr.1989;49:1283-9.

[47] Laskey MA. Dual-energy X-ray absorptiometry and body composition. Nutrition. 1996;12:45-51.

[48] Castro MJ, Apple DF Jr, Staron RS, Campos GE, Dudley GA. Influence of complete spinal cord injury on skeletal muscle within 6 mo of injury. J Appl Physiol.1999; 86:350-8.

[49] Szollar SM, Martin EM, Parthemore JG, Sartoris DJ, Deftos LJ. Densitometric patternsof spinal cord injury associated bone loss. Spinal Cord. 1997;35:374-82.

[50] Uebelhart D, Demiaux-Domenech B, Roth M, Chantraine A. Bone metabolism in spinal cord injured individuals and in others who have prolonged immobilisation. A review.Paraplegia. 1995;33:669-73.

[51] Chow YW, Inman C, Pollintine P, Sharp CA, Haddaway MJ, el Masry W, Davie MW.Ultrasound bone densitometry and dual energy X-ray absorptiometry in patients with spinal cord injury: a cross-sectional study. Spinal Cord. 1996;34:736-41.

[52] Biering-Sorensen F, Bohr H, Schaadt O. Bone mineral content of the lumbar spine and lower extremities years after spinal cord lesion. Paraplegia. 1988 ;26:293-301. 
[53] Lazo MG, Shirazi P, Sam M, Giobbie-Hurder A, Blacconiere MJ, Muppidi M. Osteoporosis and risk of fracture in men with spinal cord injury. Spinal Cord 2001;39:208-14.

[54] Frey-Rindova P, de Bruin ED, Stussi E, Dambacher MA, Dietz V. Bone mineral density in upper and lower extremities during 12 months after spinal cord injury measured by peripheral quantitative computed tomography. Spinal Cord. 2000;38:26-32.

[55] Jiang SD, Dai LY, Jiang LS. Osteoporosis after spinal cord injury. Osteoporos Int. 2006;17:180-92.

[56] Dauty M, Perrouin Verbe B, Maugars Y, Dubois C, Mathe JF. Supralesional and sublesional bone mineral density in spinal cord-injured patients. Bone. 2000;27:305-9.

[57] Chantraine A, Nusgens B, Lapiere CM. Bone remodelling during the development of osteoporosis in paraplegia. Calcif Tissue Int. 1986;38:323-7.

[58] Ogilvie C, Bowker P, Rowley DI. The physiological benefits of paraplegic orthotically aided walking. Paraplegia. 1993;31:111-5.

[59] Leslie WD, Nance PW. Dissociated hip and spine demineralization: a specific finding in spinal cord injury. Arch Phys Med Rehabil. 1993; 74:960-4.

[60] Tsuzuku S, Ikegami Y, Yabe K. Bone mineral density differences between paraplegic and quadriplegic patients: a cross-sectional study. Spinal Cord. 1999; 37:358-61.

[61] Dionyssiotis Y, Lyritis GP, Papaioannou N, Papagelopoulos P, Thomaides T. Influence of neurological level of injury in bones, muscles, and fat in paraplegia. J Rehabil Res Dev. 2009;46:1037-44.

[62] Demirel G, Yilmaz H, Paker N, Onel S. Osteoporosis after spinal cord injury. Spinal Cord. 1998;36:8

[63] Sabo D, Blaich S, Wenz W, Hohmann M, Loew M, Gerner HJ. Osteoporosis in patients with paralysis after spinal cord injury: a cross sectional study in 46 male patients with dual-energy X-ray absorptiometry. Arch Orthop Trauma Surg. 2001;121:75-8.

[64] Clasey JL, Janowiak AL, Gater DR Relationship between regional bone density measurements and the time since injury in adults with spinal cord injuries. Arch Phys Med Rehabil. 2004;85:59-64

[65] Dionyssiotis Y, Lyritis GP, Mavrogenis AF, Papagelopoulos PJ. Factors influencingbone loss in paraplegia. Hippokratia. 2011;15:54-9.

[66] de Bruin ED, Vanwanseele B, Dambacher MA, Dietz V, Stussi E. Long-term changes in the tibia and radius bone mineral density following spinal cord injury. Spinal Cord. 2005;43:96-101. 
[67] Eser P, Frotzler A, Zehnder Y, Schiessl H, Denoth J. Assessment of anthropometric, systemic, and lifestyle factors influencing bone status in the legs of spinal cord injured individuals. Osteoporos Int. 2005;16:26-34.

[68] Löfvenmark I, Werhagen L, Norrbrink C. Spasticity and bone density after a spinal cord injury. J Rehabil Med. 2009;41:1080-4.

[69] Kiratli BJ, Smith AE, Nauenberg T, Kallfelz CF, Perkash I. Bone mineral and geometric changes through the femur with immobilization due to spinal cord injury. J Rehabil Res Dev. 2000;37:225-33.

[70] Wood DE, Dunkerley AL, Tromans AM. Results from bone mineral density scans in twenty-two complete lesion paraplegics. Spinal Cord. 2001;39:145-8.

[71] Kunkel CF, Scremin AM, Eisenberg B, Garcia JF, Roberts S, Martinez S. Effect of "standing" on spasticity, contracture, and osteoporosis in paralyzed males. Arch Phys Med Rehabil. 1993;74:73-8.

[72] Frost HM. Bone "mass" and the "mechanostat": a proposal. Anat Rec. 1987;219:1-9.

[73] Frost HM. Skeletal structural adaptations to mechanical usage (SATMU): 2. Redefining Wolff's law: the remodeling problem. Anat Rec. 1990;226:414-22.

[74] Frost HM. Perspectives: on a "paradigm shift" developing in skeletal science. Calcif Tissue Int. 1995;56:1-4.

[75] Ragnarsson KT, Pollack S, O'Daniel W Jr, Edgar R, Petrofsky J, Nash MS. Clinical evaluation of computerized functional electrical stimulation after spinal cord injury: a multicenter pilot study. Arch Phys Med Rehabil. 1988;69:672-7.

[76] Belanger M, Stein RB, Wheeler GD, Gordon T, Leduc B. Electrical stimulation: can it increase muscle strength and reverse osteopenia in spinal cord injured individuals? Arch Phys Med Rehabil. 2000;81:1090-8.

[77] Bloomfield SA, Mysiw WJ, Jackson RD. Bone mass and endocrine adaptations to training in spinal cord injured individuals. Bone. 1996;19:61-8.

[78] BeDell KK, Scremin AM, Perell KL, Kunkel CF. Effects of functional electrical stimulation-induced lower extremity cycling on bone density of spinal cord-injured patients. Am J Phys Med Rehabil. 1996;75:29-34.

[79] Needham-Shropshire BM, Broton JG, Klose KJ, Lebwohl N, Guest RS, Jacobs PL. Evaluation of a training program for persons with SCI paraplegia using the Parastep 1 ambulation system: part 3. Lack of effect on bone mineral density. Arch Phys Med Rehabil. 1997;78:799-803.

[80] Shields RK. Muscular, skeletal, and neural adaptations following spinal cord injury. J Orthop Sports Phys Ther. 2002;32:65-74. 
[81] Shields RK, Dudley-Javoroski S. Musculoskeletal adaptations in chronic spinal cord injury: effects of long-term soleus electrical stimulation training. Neurorehabil Neural Repair. 2007;21:169-79.

[82] Valayer-Chaleat E, Calmels P, Giraux P, Fayolle-Minon I. Femoral fracture and iatrogenic hyperthyroidism in spinal cord injury. Spinal Cord. 1998;36:593-5.

[83] Frey Law LA, Shields RK. Femoral loads during passive, active, and active-resistive stance after spinal cord injury: a mathematical model. Clin Biomech. (Bristol, Avon). 2004;19:313-21.

[84] Fruhbeck G, Jebb SA, Prentice AM. Leptin: physiology and pathophysiology. Clin Physiol. 1998;18:399-419.

[85] Maffei M, Halaas J, Ravussin E, Pratley RE, Lee GH, Zhang Y, Fei H, Kim S, Lallone $\mathrm{R}$, Ranganathan S, et al. Leptin levels in human and rodent: measurement of plasma leptin and ob RNA in obese and weight-reduced subjects. Nat Med. 1995;1:1155-61.

[86] Bauman WA, Spungen AM, Zhong YG, Mobbs CV. Plasma leptin is directly related to body adiposity in subjects with spinal cord injury. Horm Metab Res. 1996;28:732-6.

[87] Correia ML, Morgan DA, Mitchell JL, Sivitz WI, Mark AL, Haynes WG. Role of corticotrophin-releasing factor in effects of leptin on sympathetic nerve activity and arterial pressure. Hypertension. 2001;38:384-8.

[88] Elias CF, Lee C, Kelly J, Aschkenasi C, Ahima RS, Couceyro PR, Kuhar MJ, Saper CB, Elmquist JK. Leptin activates hypothalamic CART neurons projecting to the spinal cord. Neuron. 1998;21:1375-85.

[89] Haque MS, Minokoshi Y, Hamai M, Iwai M, Horiuchi M, Shimazu T. Role of the sympathetic nervous system and insulin in enhancing glucose uptake in peripheral tissues after intrahypothalamic injection of leptin in rats. Diabetes. 1999;48:1706-12.

[90] Horowitz JF, Coppack SW, Paramore D, Cryer PE, Zhao G, Klein S. Effect of shortterm fasting on lipid kinetics in lean and obese women. Am J Physiol. 1999;276:E278-84.

[91] Horowitz JF, Klein S. Whole body and abdominal lipolytic sensitivity to epinephrine is suppressed in upper body obese women. Am J Physiol Endocrinol Metab. 2000;278:E1144-52.

[92] Krassioukov AV, Bunge RP, Pucket WR, Bygrave MA. The changes in human spinal sympathetic preganglionic neurons after spinal cord injury. Spinal Cord. 1999;37:6-13.

[93] Jeon JY, Steadward RD, Wheeler GD, Bell G, McCargar L, Harber V. Intact sympathetic nervous system is required for leptin effects on resting metabolic rate in people with spinal cord injury. J Clin Endocrinol Metab. 2003;88:402-7. 
[94] Wang YH, Huang TS, Liang HW, Su TC, Chen SY, Wang TD. Fasting serum levels of adiponectin, ghrelin, and leptin in men with spinal cord injury. Arch Phys Med Rehabil. 2005;86:1964-8.

[95] Scelsi R. Skeletal Muscle Pathology after Spinal Cord Injury: Our 20 Year Experience and Results on Skeletal Muscle Changes in Paraplegics, Related to Functional Rehabilitation Basic Appl Myol. 2001;11:75-85. 
